\title{
Photoelectric Performance of Bacteria Photosynthetic Proteins Entrapped On Tailored Mesoporous $\mathrm{WO}_{3}-\mathrm{TiO}_{2}$ Films
}

\author{
Yidong Lu', Minjia Yuan ${ }^{1}$, Yuan $\mathrm{Liu}^{2}$, Bo Tu ${ }^{1}$, Chunhe $X u^{2}$, \\ Baohong Liu ${ }^{l}$, Dongyuan Zhao ${ }^{1}$, Jilie Kong ${ }^{1 *}$
}

1.Chemistry Department, Fudan University, Shanghai 200433, China 2.Shanghai Institute of Plant Physiology, Chinese Academy of Sciences, Shanghai 200003, China 


\section{Supporting information}
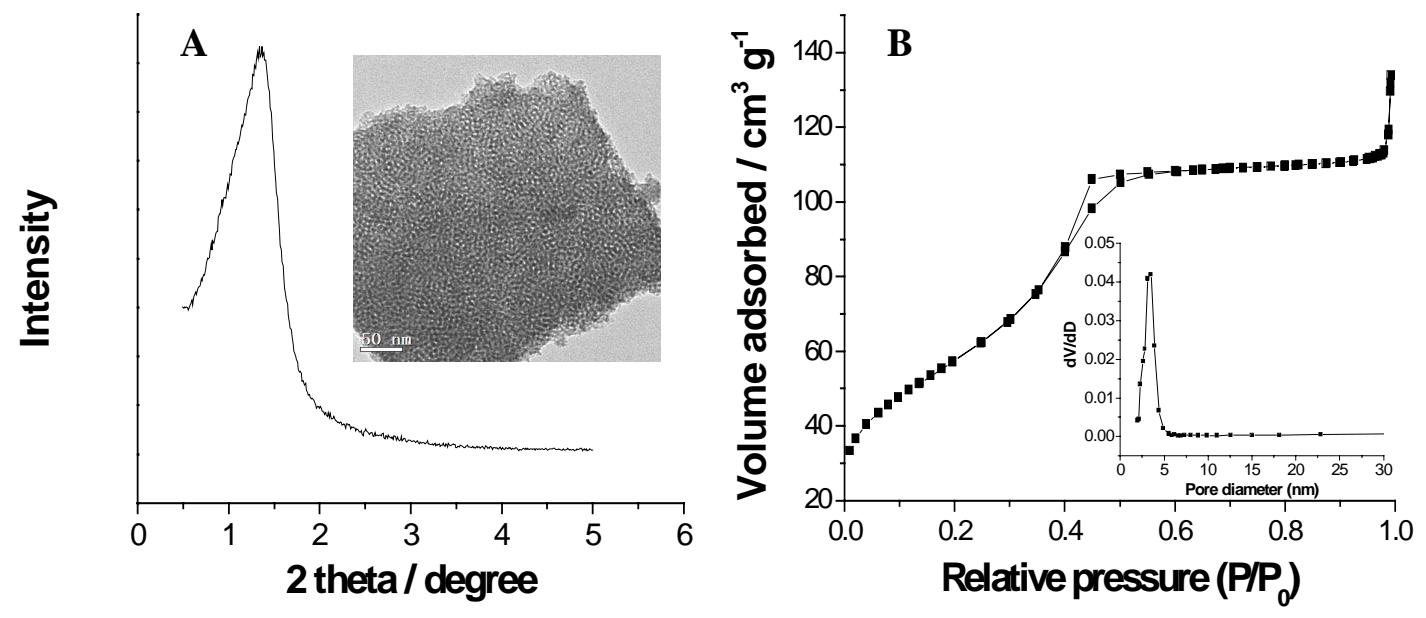

SI-Figure 1. (A) XRD pattern of calcined mesostructured $\mathrm{WO}_{3}-\mathrm{TiO}_{2}$. Inset shows the TEM image of the 3D-worm-like mesoporous $\mathrm{WO}_{3}-\mathrm{TiO}_{2}$. (B) Nitrogen sorption isotherms and pore-size distribution plots (inset) for calcined 3D-worm-like mesoporous $\mathrm{WO}_{3}-\mathrm{TiO}_{2}$ film (pore size of $3.4 \mathrm{~nm}$ ). 

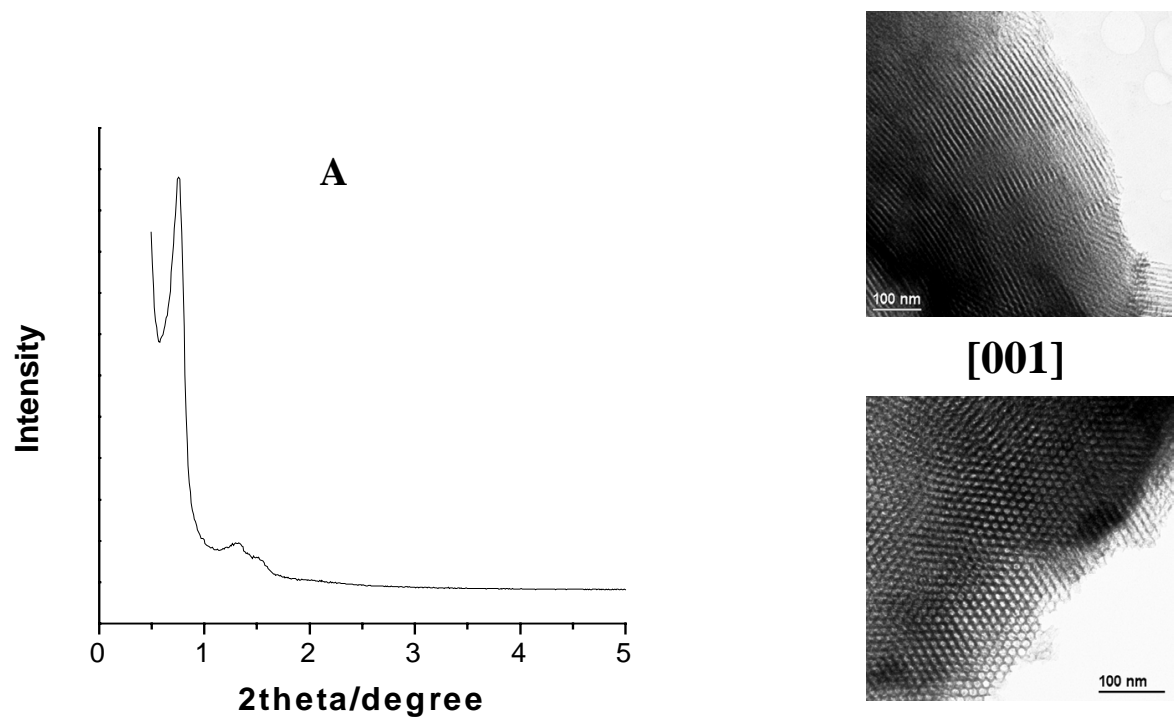

[001]

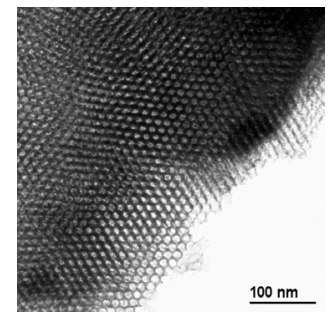

[100]

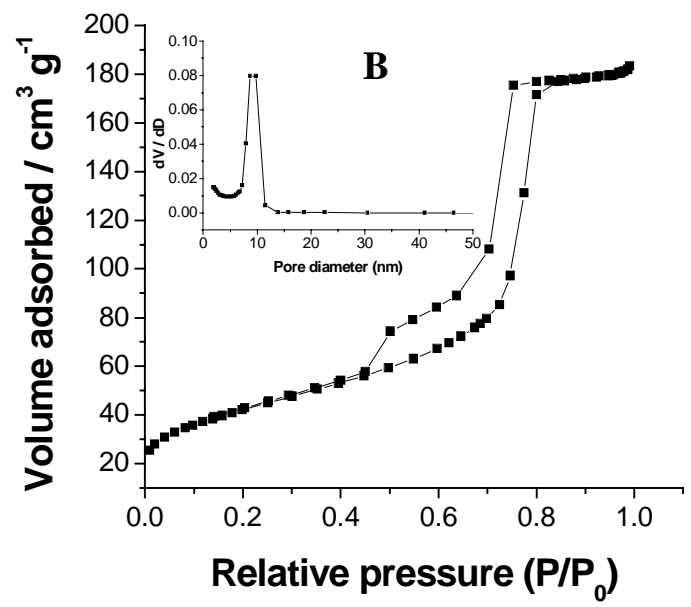

SI-Fig 2. (A) XRD pattern of calcined mesostructured $\mathrm{WO}_{3}-\mathrm{TiO}_{2}$. The right parts show the TEM image of the 2D-hexagonal mesoporous $\mathrm{WO}_{3}-\mathrm{TiO}_{2}$ viewed along [001] and [100] direction. (B) Nitrogen sorption isotherms and pore-size distribution plots (inset) for calcined 2D-hexagonal mesoporous $\mathrm{WO}_{3}-\mathrm{TiO}_{2}$ film (pore size of $9.8 \mathrm{~nm}$ ). 